\title{
Angiotensin Converting Enzyme as a Genetic Risk Factor for Coronary Artery Spasm

\author{
Implication in the Pathogenesis of Myocardial Infarction
}

\author{
Yuichi Oike, ${ }^{*}$ Akira Hata, ${ }^{\ddagger}$ Yasuhiro Ogata, ${ }^{*}$ Yuichi Numata, ${ }^{*}$ Koichi Shido, ${ }^{*}$ and Kiyotaro Kondo \\ *Department of Cardiology, Japanese Red Cross Kumamoto Hospital, Kumamoto 862, Japan; and ${ }^{\ddagger}$ Department of Public Health, \\ Hokkaido University School of Medicine, Sapporo 060, Japan
}

\begin{abstract}
It has been reported that individuals with the $D$ allele of an insertion/deletion (I/D) polymorphism of the angiotensin converting enzyme (ACE) gene are at greater risk for myocardial infarction (MI), especially among subjects normally considered to be at low risk. However, little is known about the mechanism by which the ACE polymorphism affects the risk of MI. Coronary artery spasm (CAS) is considered to be one possible mechanism for developing MI. We therefore examined the ACE polymorphism relation to CAS to determine if this was the mechanism by which the $D D$ genotype influences MI. We studied 150 angiographically assessed Japanese males, all more than $60 \mathrm{yr}$ old. CASs were detected using intracoronary injection of ergonovine maleate. Subjects were divided into three groups: those with CAS (group 1), those without CAS, but with fixed organic stenosis (group 2); and those without CAS and no organic stenosis (group 3). DD subjects were significantly represented in group 1 when compared with groups $2(P=0.002)$ and 3 $(P=0.026)$. These results suggest that the $D D$ genotype relates to the greater risk for MI in the patients with CAS. (J. Clin. Invest. 1995. 96:2975-2979.) Key words: polymorphism - coronary angiography $\bullet$ renin angiotensin system • odds ratio $\cdot$ risk factor
\end{abstract}

\section{Introduction}

Coronary heart disease is a major cause of death in most industrialized countries. Although several risk factors such as hyper-

Address correspondence to Akira Hata, Department of Public Health, Hokkaido University School of Medicine, N15, W7, Sapporo 060, Japan. Phone/FAX: 11-746-4605; E-mail: ahata@med.hokudai.ac.jp

Received for publication 29 March 1995 and accepted in revised form 12 September 1995.

1. Abbreviations used in this paper: $\mathrm{ACE}$, angiotensin converting enzyme; $\mathrm{AGT}_{1} \mathrm{R}$, angiotensin II type 1 receptor; Ang II, angiotensin II; BMI, body mass index; CAG, coronary angiography; CAS, coronary artery spasm; $D$, deletion allele; $I$, insertion allele; MI, myocardial infarction.

J. Clin. Invest.

(c) The American Society for Clinical Investigation, Inc. 0021-9738/95/12/2975/05 \$2.00

Volume 96, December 1995, 2975-2979 lipidemia, obesity, hypertension, cigarette smoking, male gender, and diabetes mellitus have been identified by epidemiological study, the genetic factors of myocardial infarction (MI) ${ }^{1}$ are poorly understood. Angiotensin converting enzyme (ACE) plays a key role in the production of angiotensin II (Ang II) and in the catabolism of bradykinin. These two peptides are involved in the modulation of vascular tone and in the proliferation of smooth muscle cells. Thus, the ACE gene is a logical etiological candidate for MI. In a multicenter study designed to identify genetic determinants of MI, Cambien et al. (1) found that the frequency of a deletion polymorphism in the ACE gene was significantly elevated in MI patients when compared with controls, especially in people otherwise classified as low risk according to their body mass index (BMI), plasma apo B, or total cholesterol. Before this study, Rigat et al. (2) showed that plasma ACE concentration is strongly associated with the ACE insertion/deletion $(I / D)$ polymorphism (i.e., ACE levels are $D D>I D>I I$ ). More recently, Tiret et al. (3) did a further study using the same subjects as the Cambien et al. study (1) and reported that the relationship between the $D$ allele and MI was greatest in those subjects with a $C$ allele of $\mathrm{A}^{1166} \rightarrow \mathrm{C}$ polymorphism (an $A \rightarrow C$ transversion at position 1166) in the Ang II type I receptor $\left(\mathrm{AGT}_{1} \mathrm{R}\right)$ gene. Other groups have studied the frequency of the $D D$ genotype in coronary artery disease. The finding of Cambien et al. (1) that the $D D$ genotype is associated with increased risk for MI is supported by reports of subjects from various ethnic backgrounds (i.e., Japanese [4, 5], a Welsh community [6], and angiographically assessed patients in Utah [7]). However, studies of Norwegian MI patients (8) and a prospective case-control study of American male physicians (9) failed to demonstrate an association between $D D$ and MI. In our analysis, we observed a positive relationship between $D D$ and MI (our unpublished data). However, the mechanism whereby ACE is involved in the pathogenesis of MI remains unknown.

In the mid 1970s, it was found that coronary artery spasm (CAS) causes variant angina (10-13). CAS is also considered to play an important role in the production of some acute myocardial infarctions $(14,15)$. A dynamic interaction between spasm, platelet aggregates, and atherosclerotic plaque may precede coronary thrombosis. Although considerable research has been done for more than a decade on CAS, with the exception of cigarette smoking (16-19), the causes and predisposing factors of CAS remain unknown.

Therefore, we hypothesized that ACE and $\mathrm{AGT}_{1} \mathrm{R}$ could be involved in the pathogenesis of MI through CAS by way of hyperreactivity of smooth muscle. In this study, we examined 
Table I. Clinical and Biological Characteristics of the Study Groups

\begin{tabular}{lccc}
\hline & $\begin{array}{c}\text { Group 1 } \\
\text { CAS(+) }\end{array}$ & $\begin{array}{c}\text { Group 2 } \\
\text { FOS(+)CAS(-) }\end{array}$ & $\begin{array}{c}\text { Group 3 } \\
\text { FOS(-)CAS(-) }\end{array}$ \\
\hline Total No. of subjects & 65 & 37 & 48 \\
Age (yr) & $68.8 \pm 0.8$ & $68.2 \pm 0.9$ & $69.1 \pm 0.9$ \\
Smoking $(q)$ & $0.75^{* \ddagger}$ & 0.54 & 0.50 \\
Total cholesterol $(\mathrm{mg} / \mathrm{dl})$ & $187.9 \pm 4.5$ & $185.8 \pm 6.9$ & $182.2 \pm 5.6$ \\
HDL cholesterol (mg/dl) & $45.2 \pm 1.6^{8} \|$ & $39.6 \pm 1.6^{\S}$ & $55.7 \pm 2.5$ \\
Triglyceride (mg/dl) & $132.2 \pm 7.9$ & $148.8 \pm 13.3$ & $130.8 \pm 12.0$ \\
Uric acid $(\mathrm{mg} / \mathrm{dl})$ & $6.1 \pm 0.2$ & $5.8 \pm 0.3$ & $6.2 \pm 0.3$ \\
BMI $\left(\mathrm{kg} \mathrm{m} \mathrm{m}^{-2}\right)$ & $22.3 \pm 0.5$ & $23.5 \pm 0.5$ & $22.9 \pm 0.5$ \\
Hypertension $(q)$ & 0.43 & 0.49 & 0.57 \\
Coronary artery & & & \\
$\quad$ No stenosis & $36(55.4 \%)$ & $0(0 \%)$ & $48(100 \%)$ \\
1VD & $19(29.2 \%)$ & $17(46.0 \%)$ & $0(0 \%)$ \\
2VD & $9(13.9 \%)$ & $13(35.1 \%)$ & $0(0 \%)$ \\
3VD & $1(1.5 \%)$ & $7(18.9 \%)$ & $0(0 \%)$ \\
& & & \\
\hline
\end{tabular}

All individuals are male and $>60 \mathrm{yr}$ old. Subjects with hypertrophic cardiomyopathy, dilated cardiomyopathy, and left ventricular hypertrophy were excluded. Values are mean \pm SE. FOS, fixed organic stenosis; $q$, frequency; $I V D$, single-vessel disease; $2 V D$, double-vessel disease; $3 V D$, triple-vessel disease. ${ }^{*} P=0.009$ vs. group $3,{ }^{\ddagger} P=0.031$ vs. group 2 by Fisher's two-tailed exact test. ${ }^{8} P<0.01$ vs. group 3 , " $P$ $<0.05$ vs. group 2 by Student's $t$ test.

this hypothesis by analyzing CAS in a variety of patients who had complained of chest pain. We found a significant association between the $D D$ genotype and CAS. Therefore, $D D$ individuals may be at high risk for CAS, thus also for MI.

\section{Methods}

Patients. All subjects in this study were Japanese and were seen in our outpatient clinic because of complaints of chest pain. From June 1993 to February 1994, all subject's DNA was collected. All subjects were hospitalized and coronary angiographed. Subjects with hypertrophic cardiomyopathy, dilated cardiomyopathy, and left ventricular hypertrophy were excluded from this study, as previous reports indicated that these diseases are associated with ACE polymorphism. Subjects for whom ergonovine maleate provocation is dangerous as judged by coronary angiography (CAG) findings were also excluded. Finally, men $<60 \mathrm{yr}$ old and all women were excluded to match sex and age among the groups defined below. Subjects were classified into three groups under the following criteria (Table I). Group 1 consisted of 65 patients with CAS during ergonovine maleate provocation in one or more of the epicardial coronary arteries monitored by CAG. All patients had no coronary artery luminal narrowing of $>75 \%$ after administration of isosorbide dinitrate. All patients had attacks of chest pain at rest but no one had exertional chest pain. CAS was defined when both criteria were met: (a) total or $99 \%$ occlusion monitored with radiopaque delayed imaging by CAG; and $(b)$ significant ST segment alterations (at least $0.1 \mathrm{mV}$ of elevation or $0.2 \mathrm{mV}$ depression from at least two contiguous leads) monitored by a standard 12-lead electrocardiogram (ECG). Group 2 consisted of 37 patients with coronary artery luminal narrowing of $>75 \%$ after administration of isosorbide dinitrate. In group 2, all coronary arteries had no reaction after ergonovine maleate provocation. All 37 patients had significant ST segment depression with or without chest pain during exercise. Group 3 consisted of 48 subjects with angiographically normal coronary arteries, and during ergonovine maleate provocation the luminal diameter was reduced by $25 \%$ or less. In this group, exercise did not significantly alter the ST segment, and chest pain was not relieved by sublingual nitrates.

Risk factors. Patients who smoked at least 10 cigarettes/d for $>5$ yr were considered smokers. Subjects were considered to have hypertension if they met the criteria of the World Health Organization or if they were already being treated. Plasma HDL cholesterol level $<40 \mathrm{mg} / \mathrm{dl}$ was defined as abnormally low.

Coronary angiography. Informed written consent was obtained from each patient before cardiac catheterization and ergonovine provocation testing. CAG was performed by the Sones technique (20) after the withdrawal of ACE inhibitors, calcium antagonists, $\beta$-blockers, and nitrates for at least $48 \mathrm{~h}$. The right coronary artery was visualized in the left anterior oblique view and the left coronary artery in the right anterior oblique view. Then a catheter was placed in the left and then right coronary ostium, and $8 \mu \mathrm{g} / \mathrm{min}$ of ergonovine maleate was injected directly into the coronary artery for $4 \mathrm{~min}$. If the patients felt chest discomfort or if significant ST segment alterations occurred, administration of ergonovine maleate was stopped immediately, and CAG was performed. In case of no chest discomfort or ECG changes, CAG was performed after the full $4 \mathrm{~min}$ of ergonovine administration. Then, intracoronary isosorbide dinitrate was given, and CAG was obtained in multiple projections as follows. The left coronary artery was visualized in four angulations; a right anterior oblique $35^{\circ}$ view, a right anterior oblique $35^{\circ}$ and caudal $25^{\circ}$ view, a left anterior oblique $55^{\circ}$ and cranial $25^{\circ}$ view, and a left anterior oblique $55^{\circ}$ view. The right coronary artery was visualized in a left anterior oblique $55^{\circ}$ view, and in a right anterior oblique $35^{\circ}$ view. When a stenotic region was observed, an additional projection was used to obtain optimal visualization. During the study, arterial blood pressure and ECG were monitored continuously on an oscilloscope of model EP 1100 polygraph (NEC Co., Tokyo, Japan) and recorded using a model 8M15 Omnicorder (NEC Co.). Chest leads used were radiolucent carbon electrodes. Conditions of coronary arteries were described following the criteria of the American Heart Association Committee Report (21) by two independent investigators.

Serum ACE measurement. Serum ACE activity was measured in duplicate by a colorimetric method based on the quinoneimine dye produced from the substrate of $\rho$-hydroxybenzoyl-glycyl-L-histidyl-Lleucine (22). The subjects measured were selected randomly from our outpatient clinic.

DNA studies. DNA was extracted from peripheral blood by use of a DNA extractor WB kit (Wako, Osaka, Japan). Genotyping of ACE $I / D$ and $A G T{ }_{1} \mathrm{R}^{1166} \rightarrow \mathrm{C}$ polymorphisms was assayed by DNA amplification. For ACE genotyping, the sequences of the sense primer and the antisense primer were 5'-CTGGAGACCACTCCCATCCTTTCT$3^{\prime}$ and 5'-GATGTGGCCATCACATTCGTCAGAT-3', respectively. Reactions were performed in a final volume of $25 \mu \mathrm{l}$ containing $5 \mathrm{pmol}$ of each primer, $2.0 \mathrm{mM} \mathrm{MgCl}, 50 \mathrm{mM} \mathrm{KCl}, 10 \mathrm{mM}$ Tris- $\mathrm{HCl}(\mathrm{pH}$ $8.4), 0.1 \mathrm{mg} / \mathrm{ml}$ gelatin, $0.1 \mathrm{mM}$ of each dNTP, and $0.5 \mathrm{U}$ Taq polymerase (Perkin Elmer Co., Foster, CA). The DNA was amplified for 30 cycles with denaturation at $94^{\circ} \mathrm{C}$ for $60 \mathrm{~s}$, annealing at $64^{\circ} \mathrm{C}$ for $45 \mathrm{~s}$, and extension at $72^{\circ} \mathrm{C}$ for $60 \mathrm{~s}$ using a Thermal Cycler 480 (Perkin Elmer Co.). The PCR products were separated by $2 \%$ agarose gel electrophoresis, and DNA was visualized directly with ethidium bromide staining. We confirmed the accuracy of the genotyping results in the $D D$ homozygotes by using an insertion-specific primer, because the $D$ allele is preferentially amplified versus the $I$ allele (23). For AGT $_{1} R$ genotyping, allele-specific oligonucleotide hybridization after amplification of the gene was performed, using the primers, probes, and other experimental conditions described by Bonnardeaux et al. (24), except we used the digoxigenin system (Boehringer Mannheim, Indianapolis, IN) for hybridization.

Statistical analysis. All statistical analyses were conducted by use of a statistical analysis system package (SAS Institute Inc., Cary, NC). Data of ACE activity, age, total cholesterol, HDL cholesterol, triglyceride, uric acid, and BMI were presented as mean \pm standard error. The differences between groups were analyzed by the unpaired Student's $t$ test. The differences in frequencies of smoking, hypertension, and ACE genotypes were analyzed by Fisher's exact test. All $P$ values are two- 
Table II. Distribution of the ACE and $A G T_{1} R$ Genotypes

\begin{tabular}{llcc}
\hline & $\begin{array}{c}\text { Group 1 } \\
\text { CAS(+) }\end{array}$ & $\begin{array}{c}\text { Group 2 } \\
\text { FOS(+)CAS(-) }\end{array}$ & $\begin{array}{c}\text { Group 3 } \\
\text { FOS(-)CAS(-) }\end{array}$ \\
\hline $\begin{array}{l}\text { Total No. of subjects } \\
\text { ACE genotype }\end{array}$ & 65 & 37 & 48 \\
$\quad D D$ & 17 & 1 & 4 \\
$I D$ & 21 & 16 & 27 \\
$I I$ & 27 & 20 & 17 \\
DD & $17^{* \ddagger}$ & 1 & 4 \\
$I D+I I$ & 48 & 36 & 44 \\
Frequency of allele $D$ & 0.42 & 0.24 & 0.36 \\
AGT ${ }_{1}$ genotype & & & \\
$C C$ & 0 & 0 & 0 \\
$A C$ & $6^{\S}$ & 9 & 40 \\
$A A$ & 59 & 28 & 0.08 \\
Frequency of allele $C$ & 0.05 & 0.12 & \\
& & &
\end{tabular}

All patients are male and $>60 \mathrm{yr}$ old. ${ }^{*} P=0.026$ vs. group $3,{ }^{\ddagger} P$ $=0.002$ and ${ }^{\S} P=0.047$ vs. group 2 by Fisher's two-tailed exact test.

tailed. A value of $P<0.05$ is considered statistically significant. A multiple logistic model was applied to evaluate how combinations of risk factors elevate the risks compared with a reference group without any risk factors. Only risk factors detected by univariate analysis as significant between groups were subjected to a stepwise regression analysis.

\section{Results}

Subjects were divided into three groups. Clinical and biological parameters are listed in Table I (for more in-depth details, see Methods). Cigarette smoking was significantly more prevalent in groups 1 versus groups 2 and 3, which is consistent with previous studies (16-19). There were significant differences in HDL cholesterol levels among the three groups. Group 3 has the highest level, while group 2 has the lowest. HDL cholesterol levels were significantly lower in both groups 1 and 2 compared with group 3 (both $P<0.01$ ) and also when group 2 was compared with group $1(P<0.05)$. No differences could be detected among the three groups for age, total cholesterol, triglyceride, uric acid, BMI, or prevalence of hypertension. In group $1,55.4 \%$ of the subjects have no stenosis of coronary arteries.

The distribution of the ACE and $\mathrm{AGT}_{1} \mathrm{R}$ genotypes of the three groups is shown in Table II. The $D$ allele frequency of the ACE gene in our study population was 0.36 , which is close to values reported in other Japanese populations (25). In this study, the vast majority of $D D$ subjects was in the CAS group (group 1). The $D D$ frequency in group 1 is significant compared with group $2(P=0.002)$ and group $3(P=0.026)$. On the other hand, the $C$ allele frequency of the $\mathrm{AGT}_{1} \mathrm{R}$ gene in 423 Japanese subjects was 0.09 , which is significantly low compared with a reported frequency $(q=0.29)$ in Caucasians (3). There were no subjects with $C C$ genotype in our study group. The frequency of subjects with the $A C$ genotype is low in group 1 compared with group 2 in marginal significance $(P=0.047)$.

By univariate analysis of the above-mentioned factors, only
Table III. Synergistic Effects of Selected Risk Factors

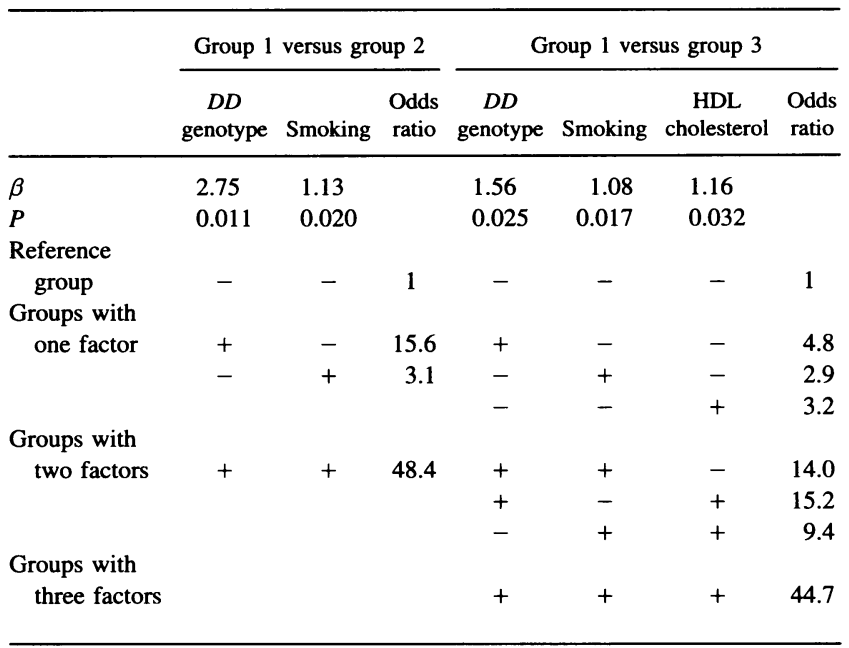

A multiple logistic model was applied to evaluate the risks compared with a reference group with none of the risk factors. Four factors (group 1 versus group 2 ) and three factors (group 1 versus group 3), which were significant by univariate analysis, were subjected to a stepwise regression analysis to select significant factors. Only the factors for the groups listed above were found to be significant by this method.

smoking, $D D$ genotype, HDL cholesterol level, and $\mathrm{AGT}_{1} \mathrm{R}$ genotype (only for group 1 versus group 2 ) were significant for CAS. Therefore multivariate analyses were performed using these variables. Only smoking and $D D$ genotype were found to be significant factors when groups 1 and 2 were compared. The odds ratio when both smoking and $D D$ were combined is 48.4 (Table III). For group 1 versus group 3, all three factors were significant, and, when combined, the odds ratio was 44.7 (Table III). Among 17 subjects with $D D$ genotype in group 1,11 subjects were with smoking and 6 with all three factors.

As shown in Table IV, serum levels of ACE were $27.0 \pm 1.0$, $23.2 \pm 0.9$, and 18.8 $\pm 0.9 \mathrm{IU} /$ liter for genotypes $D D, I D$, and $I I$, respectively. The mean plasma $A C E$ level in $D D$ subjects was about twice that of $I I$ subjects $(P<0.001)$, with $I D$ subjects having intermediate levels. These findings are similar to those observed in previous studies $(2,5)$.

\section{Discussion}

In this report, we have clearly demonstrated an association of the $D D$ genotype and CAS induced by intracoronary injection of ergonovine maleate. However, it must be pointed out that association studies can give false positive results. It is now

Table IV. Serum ACE Levels in Groups with Different ACE Genotypes

\begin{tabular}{lccc}
\hline & \multicolumn{3}{c}{ ACE genotype } \\
\cline { 2 - 4 } & $D D$ & $I D$ & $I I$ \\
\hline$N$ & 25 & 87 & 98 \\
ACE (IU/liter) & $27.0 \pm 1.0^{*}$ & $23.2 \pm 0.9 *$ & $18.8 \pm 0.9$ \\
\hline
\end{tabular}

Values are mean \pm SE. $* P<0.001$ vs. II genotype by Student's $t$ test. 
generally accepted that CAS not only is the cause of variant angina but also represents a pathogenetic component in other ischemic heart disease syndromes such as MI (26). However, the precise mechanism by which CAS occurs remains to be elucidated. Serotonin and other vasoactive substances have been reported to cause vasoconstriction in atherosclerotic blood vessels, which are associated with defective endothelial-dependent vasodilation. Thus, endothelial dysfunction has been implicated as a cause of CAS in patients with variant angina $(12,27)$, as intracoronary infusion of acetylcholine at a high dose provokes CAS. However, acetylcholine has a direct vasoconstricting action on vascular smooth muscle in addition to a vasodilating action mediated by the endothelium. Thus, provocation of CAS by acetylcholine may result from enhanced vasoconstricting responses of vascular smooth muscle, not to endothelial dysfunction. Egashira et al. (28) and Yamamoto et al. (29) studied whether endothelium-dependent vasodilation was impaired at the vasospastic site in patients with variant angina using substance $P$. Their findings suggest that acetylcholine- or ergonovine-induced CAS results from hyperreactivity of vascular smooth muscle, not from endothelial dysfunction. The same conclusion was reached using an in vivo swine model (30). These data seem to indicate that smooth muscle hyperreactivity is one of the major mechanisms of CAS.

In this study, we observed higher serum ACE levels in $D D$ subjects than in ID and II subjects, which agrees with other reports $(2,5)$ (Table IV). The renin angiotensin system is present in vascular cells (31). However, the major source of renin in vascular cells is thought to be the kidney (32), as endogenous renin expression is too low to account for intracellular renin levels (33). Reports by several investigators suggest that in vivo increases in local vascular ACE activity result in parallel increases in tissue Ang I conversion to Ang II with corresponding changes in local function (34-37). These data suggest that local tissue ACE may be rate limiting in regulating local Ang II production. Furthermore, ACE is known to degrade bradykinin, a potent vasodilator, which may also help to accelerate vasoconstricting responses. Knowing this, it is tempting to speculate that $D D$ individuals have higher tissue ACE levels than $I I$ individuals, and that coronary smooth muscle is hyperreactive in $D D$ individuals via increased levels of Ang II and/ or decreased levels of bradykinin. Our findings that $D D$ is a significant risk factor for CAS support such a hypothesis.

In the report by Cambien et al. (1), the association between the $D D$ genotype and MI was significant in the low-risk group defined by plasma apo B level, hypolipidemic treatment, and BMI, or when low risk was defined using total cholesterol or LDL cholesterol instead of apo B. One possible way to relate the Cambien et al. (1) data with our data is to assume that CAS caused some, not all, of the MIs. Patients in their low risk group would be assigned to our group 1. For these patients, a significant percentage of MI was caused by CAS. Thus, we have the observed significance of $D D$. Patients in their high risk groups would be assigned to our group 2. For these patients, a significant percentage of MI was not caused by CAS. In both their report and our report, for group 2 (like) subjects, $D D$ was not significant for MI and CAS, respectively. Furthermore, Ludwig et al. (7) claimed that among patients with coronary artery disease (defined by $>60 \%$ stenosis in any major coronary vessel) the occurrence of MI was significantly associated with the $D$ allele. We feel that their data could also be explained by the existence of a significant number of CAS patients that caused MI with the $D$ allele(s). In the low risk group defined by smoking, Cambien et al. (1) found no association between $D D$ and MI. This seems to indicate that the existence of patients with CAS caused MI in their high risk group defined by smoking. Our finding that smoking and the $D D$ genotype have a synergistic effect on CAS (Table III) does not conflict with this explanation.

We could not confirm the interaction of $A C E$ and $A_{G T} T_{1} R$ proposed by Tiret et al. (3) by multivariate analysis, although we found the frequency of subjects with $A C$ genotype in group 1 to be significantly low compared with group $2(P=0.047)$ (Table II). The frequency of the $C$ allele $(q=0.09)$ in this study was much lower than in the Tiret (3) paper $(q=0.29)$, which is too low to get a meaningful result with our sample size. Therefore, this study does not provide any substantial information about this interaction.

\section{Acknowledgments}

We thank Dr. Tomio Wakita and Dr. Takeshi Tsuji for blood drawing, Dr. John F. Maune for critical assistance in manuscript preparation, and Dr. Koichi Nakao for helpful suggestions.

This work was supported in part by a grant-in-aid of the Japanese Ministry of Education, Science and Culture, a grant of the Japan Medical Association, and a grant of Chiyoda Mutual Life Foundation.

\section{References}

1. Cambien, F., O. Poirier, L. Lecerf, A. Evans, J.-P. Cambou, D. Arveiler, G. Luc, J.-M. Bard, L. Bara, S. Ricard, et al. 1992. Deletion polymorphism in the gene for angiotensin-converting enzyme is a potent risk factor for myocardial infarction. Nature (Lond.). 359:641-644.

2. Rigat, B., C. Hubert, F. Alhenc-Gelas, F. Cambien, P. Corvol, and F. Soubrier. 1990. An insertion/deletion polymorphism in the angiotensin I-converting enzyme gene accounting for half the variance of serum enzyme levels. $J$. Clin. Invest. 86:1343-1346.

3. Tiret, L., A. Bonnardeaux, O. Poirier, S. Ricard, P. Marques-Vidal, A. Evans, D. Arveiler, G. Luc, F. Kee, P. Ducimetiere, et al. 1994. Synergistic effects of angiotensin-converting enzyme and angiotensin-II type 1 receptor gene polymorphisms on risk of myocardial infarction. Lancet. 344:910-913.

4. Zhao, Y., K. Higashimori, J. Higaki, A. Kamitani, M. Ohishi, T. Katsuya, T. Miki, H. Mikami, T. Minamino, and T. Ogihara. 1994. Significance of the deletion polymorphism of the angiotensin converting enzyme gene as a risk factor for myocardial infarction in Japanese. Hypertens. Res. 17:55-57.

5. Nakai, K., C. Itoh, Y. Miura, K. Hotta, T. Musha, T. Itoh, T. Miyakawa, R. Iwasaki, and K. Hiramori. 1994. Deletion polymorphism of the angiotensin Iconverting enzyme gene is associated with serum ACE concentration and increased risk for CAD in the Japanese. Circulation. 90:2199-2202.

6. Mattu, R. K., E. W. A. Needham, D. J. Galton, E. Frangos, A. J. L. Clark, and M. Caulfield. 1995. A DNA variant at the angiotensin-converting enzyme gene locus associates with coronary artery disease in the Caerphilly heart study. Circulation. 91:270-274.

7. Ludwig, E., P. S. Corneli, J. L. Anderson, H. W. Marshall, J.-M. Lalouel, and R. H. Ward. 1995. Angiotensin-converting enzyme gene polymorphism is associated with myocardial infarction but not with development of coronary stenosis. Circulation. 91:2120-2124.

8. Bohn, M., K. E. Berge, A. Bakken, J. Erikssen, and K. Berg. 1993. Insertion/ deletion (I/D) polymorphism at the locus for angiotensin I-converting enzyme and myocardial infarction. Clin. Genet. 44:292-297.

9. Lindpaintner, K., M. A. Pfeffer, R. Kreutz, M. J. Stampfer, F. Grodstein F. LaMotte, J. Buring, and C. H. Hennekens. 1995. A prospective evaluation of an angiotensin-converting-enzyme gene polymorphism and the risk of ischemic heart disease. N. Engl. J. Med. 332:706-711.

10. Oliva, P. B., D. E. Potts, and R. G. Pluss. 1973. Coronary arterial spasm in Prinzmetal angina. Documentation by coronary arteriography. N. Engl. J. Med. 288:745-751.

11. Maseri, A., R. Mimmo, S. Chierchia, C. Marchesi, A. Pesola, and A. L'Abbate. 1975. Coronary artery spasm as a cause of acute myocardial ischemia in man. Chest. 68:625-633.

12. Yasue, H., Y. Horio, N. Nakamura, H. Fujii, N. Imoto, R. Sonoda, K. Kugiyama, K. Obata, Y. Morikami, and T. Kimura. 1986. Induction of coronary artery spasm by acetylcholine in patients with variant angina: possible role of the 
parasympathetic nervous system in the pathogenesis of coronary artery spasm. Circulation. 74:955-963.

13. Endo, M., K. Hirosawa, N. Kaneko, K. Hase, Y. Inoue, and S. Konno. 1976. Prinzmetal's variant angina. Coronary arteriogram and left ventriculogram during angina attack induced by methacholine. N. Engl. J. Med. 294:252-255.

14. Oliva, P. B., and J. C. Breckinridge. 1977. Arteriographic evidence of coronary arterial spasm in acute myocardial infarction. Circulation. 56:366-374.

15. Maseri, A., A. L'Abbate, G. Baroldi, S. Chierchia, M. Marzilli, A. M. Ballestra, S. Severi, O. Parodi, A. Biagini, A. Distante, and A. Pesola. 1978. Coronary vasospasm as a possible cause of myocardial infarction. A conclusion derived from the study of "preinfarction" angina. N. Engl. J. Med. 299:12711277.

16. Scholl, J.-M., A. Benacerraf, P. Ducimetiere, D. Chabas, J. Brau, J. Chapelle, and J.-L. Thery. 1986. Comparison of risk factors in vasospastic angina without significant fixed coronary narrowing to significant fixed coronary narrowing and no vasospastic angina. Am. J. Cardiol. 57:199-202.

17. Caralis, D. G., U. Deligonul, M. J. Kern, and J. D. Cohen. 1992. Smoking is a risk factor for coronary spasm in young women. Circulation. 85:905-909.

18. Nobuyoshi, M., M. Abe, H. Nosaka, T. Kimura, H. Yokoi, N. Hamasaki, T. Shindo, K. Kimura, T. Nakamura, Y. Nakagawa, et al. 1992. Statistical analysis of clinical risk factors for coronary artery spasm: identification of the most important determinant. Am. Heart J. 124:32-38.

19. Sugiishi, M., and F. Takatsu. 1993. Cigarette smoking is a major risk factor for coronary spasm. Circulation. 87:76-79.

20. Sones, F. M., Jr., and E. K. Shirey. 1962. Cine coronary arteriography. Mod. Conc. Cardiov. Dis. 31:735-738.

21. Austen, G., J. E. Edwards, R. L. Frye, G. G. Gensini, V. L. Gott, L. S. C. Griffith, D. C. McGoon, M. L. Murrhy, and B. B. Roe. 1975. AHA committee report. A reporting system on patients evaluated for coronary artery disease. News from the American Heart Association. 7-40.

22. Kasahara, Y., and Y. Ashihara. 1981. Colorimetry of angiotensin-I converting enzyme activity in serum. Clin. Chem. 27:1922-1925.

23. Shanmugam, V., K. W. Sell, and B. K. Saha. 1993. Mistyping ACE heterozygotes. PCR Methods Appl. 3:120-121.

24. Bonnardeaux, A., E. Davies, X. Jeunemaitre, I. Fery, A. Charru, E. Clauser, L. Tiret, F. Cambien, P. Corvol, and F. Soubrier. 1994. Angiotensin II type 1 receptor gene polymorphisms in human essential hypertension. Hypertension (Dallas). 24:63-69.

25. Iwai, N., N. Ohmichi, Y. Nakamura, and M. Kinoshita. 1994. DD genotype of the angiotensin-converting enzyme gene is a risk factor for left ventricular hypertrophy. Circulation. 90:2622-2628.

26. Maseri, A., G. Davies, D. Hackett, and J. C. Kaski. 1990. Coronary artery spasm and vasoconstriction. The case for a distinction. Circulation. 81:19831991.

27. Vanhoutte, P. M., and H. Shimokawa. 1989. Endothelium-derived relaxing factor and coronary vasospasm. Circulation. 80:1-9.

28. Egashira, K., T. Inou, A. Yamada, Y. Hirooka, and A. Takeshita. 1992. Preserved endothelium-dependent vasodilation at the vasospastic site in patients with variant angina. J. Clin. Invest. 89:1047-1052.

29. Yamamoto, H., H. Yoshimura, M. Noma, H. Kai, S. Suzuki, T. Tajimi, M. Sugihara, and Y. Kikuchi. 1992. Preservation of endothelium-dependent vasodilation in the spastic segment of the human epicardial coronary artery by substance P. Am. Heart J. 123:298-303.

30. Fukai, T., K. Egashira, H. Hata, K. Numaguchi, Y. Ohara, T. Takahashi, H. Tomoike, and A. Takeshita. 1993. Serotonin-induced coronary spasm in a swine model. A minor role of defective endothelium-derived relaxing factor. Circulation. 88:1922-1930.

31. Dzau, V. J. 1986. Significance of the vascular renin-angiotensin pathway. Hypertension (Dallas). 8:553-559.

32. Kato, H., N. Iwai, H. Inui, K. Kimoto, Y. Uchiyama, and T. Inagami 1993. Regulation of vascular angiotensin release. Hypertension (Dallas). 21:446454.

33. Paul, M., J. Wagner, and V. J. Dzau. 1993. Gene expression of the reninangiotensin system in human tissues. Quantitative analysis by the polymerase chain reaction. J. Clin. Invest. 91:2058-2064.

34. Okamura, T., M. Miyazaki, T. Inagami, and N. Toda. 1986. Vascular renin-angiotensin system in two-kidney, one clip hypertensive rats. Hypertension (Dallas). 8:560-565.

35. Shunkert, H., V. J. Dzau, S. S. Tang, A. T. Hirsch, C. S. Apstein, and B. H. Lorell. 1990. Increased rat cardiac angiotensin converting enzyme activity and mRNA expression in pressure overload left ventricular hypertrophy. Effects on coronary resistance, contractility, and relaxation. J. Clin. Invest. 86:19131920.

36. Rakugi, H., D.-K. Kim, J. E. Krieger, D. S. Wang, V. J. Dzau, and R. E. Pratt. 1994. Induction of angiotensin converting enzyme in the neointima after vascular injury. Possible role in restenosis. J. Clin. Invest. 93:339-346.

37. Morishita, R., G. H. Gibbons, K. E. Ellison, W. Lee, L. Zhang, H. Yu Y. Kaneda, T. Ogihara, and V. J. Dzau. 1994. Evidence for direct local effect of angiotensin in vascular hypertrophy. In vivo gene transfer of angiotensin converting enzyme. J. Clin. Invest. 94:978-984. 